\title{
STABILITY CALCULATION OF ROD ELEMENTS OF SOLID-WALL ARCHES BY THE FLEXURAL-TORSIONAL FORM
}

\author{
Dmitrii Urazgildeev, Grigorii Beliy² \\ 1,2 Saint Petersburg State University of Architecture and Civil Engineering \\ Vtoraja Krasnoarmejskaja ul. 4, St. Petersburg, Russia \\ 1 urazgildeev.dmitry@yandex.ru
}

\begin{abstract}
The work considers main, most significant scientific works on study of the stability of rods with the curved axis; the issue of the subject matter investigation is examined. A procedure for determining the spatial displacements of curvilinear rods during the elastic work of the material is proposed. An for the assessment of the stress-strain behavior of the rod element with the curved axis by the criterion of fibrous yield is given. As the algorithm illustration, an example is given of selecting a section of a steel arch.
\end{abstract}

Keywords
Stability, solid-wall steel arch, curved axis rod, thin-walled rod.

\section{Introduction}

Steel arches for roof-bearing structures appeared in 1940-1950s. Besides their architectural expressiveness, arches have a doubtless advantage over beam and frame structures due to considerably smaller bending moments occurring in structure sections. Decrease of the bending moment in arches is achieved due to a thrust which creates a moment, opposite in sign to the moment from external forces, in each structural section. In this connection, the main design value for the arch is not the bending moment, but the axial load. In designing of metal arches, the determining factor, when assessing the operation capability of a structure, is not the ability to resist bending, but the ability to maintain the axis shape (stability). The loss of stability by a curved axis rod has more complex nature than the loss of stability by a straight rod.

\section{Background}

Many scientists studied the stability of straight and curved axis rods of open profile. S.P. Timoshenko was one of the first who considered the problem of the stability of a curved axis rod. In his work (Timoshenko, 1971), he provided the derivation of a differential equation of the stability of the plane bending of a curved axis rod. The contribution of V.Z. Vlasov to this study should be noted too. He developed a technical theory of calculating thin-walled rods of open profile; this theory was the basis for many scientific works related to the stress-strain state of thin-walled rods. In his work (Vlasov, 1959), Vlasov considered various particular problems related to the stability of thin-walled circular rods, arches and toroid-shape shells. Works of A.A. Umansky should be specially mentioned; the author developed a theory of rods of closed profile.

The deformation theory by Vlasov for calculating thin-walled rods was worked out in papers of B.M. Broude, L.N. Vorobyev and was generalized by E.A. Beylin.

In speaking of the calculation of a thin-walled curved axis rod by the stress-strain scheme, it is necessary to mention works of E.A. Beylin (Beylin, 1997; Beylin, 1970), as well as G.I. Beliy (Beliy, 1973), who considered in his scientific work a number of particular problems related to performance of curved axis rods under various loads and boundary conditions.

\section{Challenging issues of the study}

The use of arched structures in large-span buildings allows for significant decrease in steel consumption. However, their large-scale implementation is restrained by the lack of directions for stability calculations in domestic design standards; meanwhile, researches, which are available in this area, do not allow developing an engineering calculation procedure. Therefore, one of relevant directions of research is the study of the spatial stability of curved axis rods in order to obtain an engineering technique for the calculation of solid-wall arches. 
Algorithm of the stress-strain calculation for the stability of an arch rod element by the flexural-torsional form

Let us consider a problem of the stability of plane bending of a thin-walled rod element selected from a solid-wall arch (see Figure 1).

The considered fragment is located between points of the arch bracing out of the plane - between runs. The length of the rod element is assumed to be equal to its geometric length. The element is loaded with the axial force $\mathrm{F}$ applied with eccentricities relative to both axes of symmetry ex and ey, as shown in Figure 2a. Ends of the arch are hinged in the plane and out of the plane of the initial curvature; curling of arch ends is absent.

The selected rod element of the symmetrical section is hinged in the plane and out of the initial curvature plane; there is no curling of the end sections.

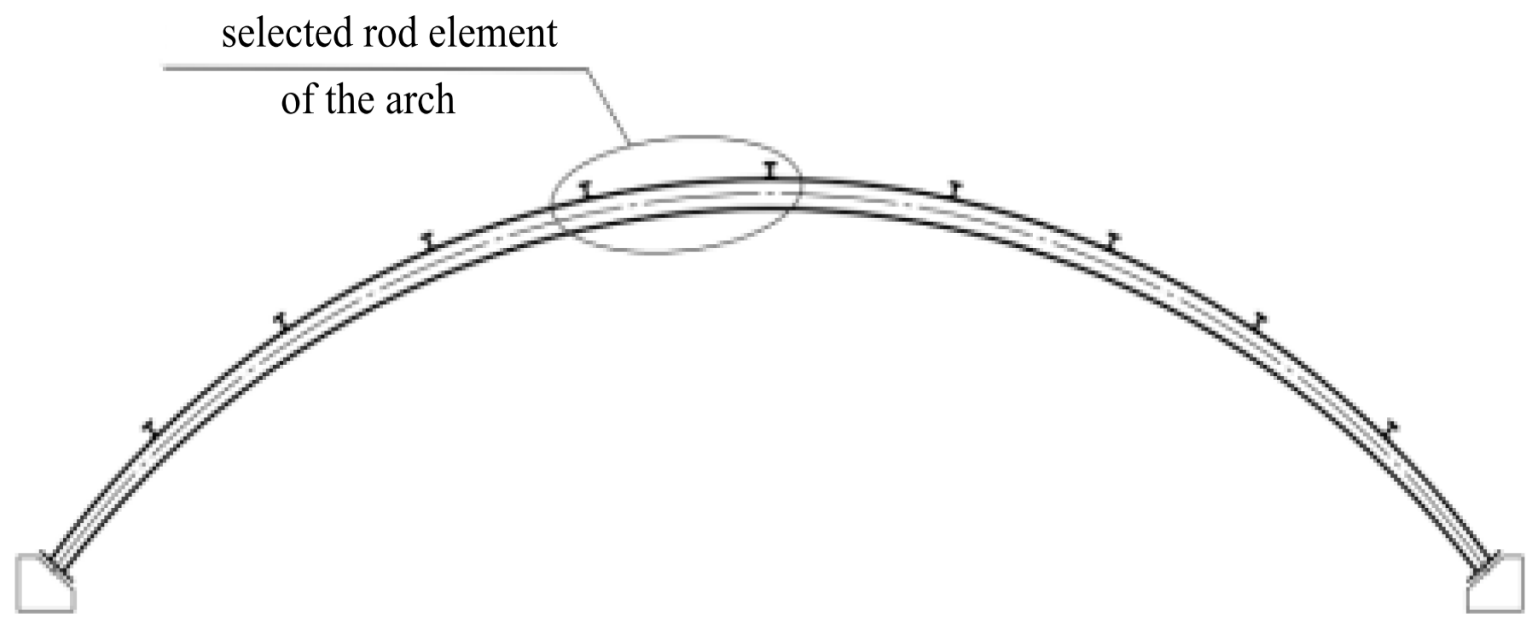

Figure 1. Selection of a rod element from the structure

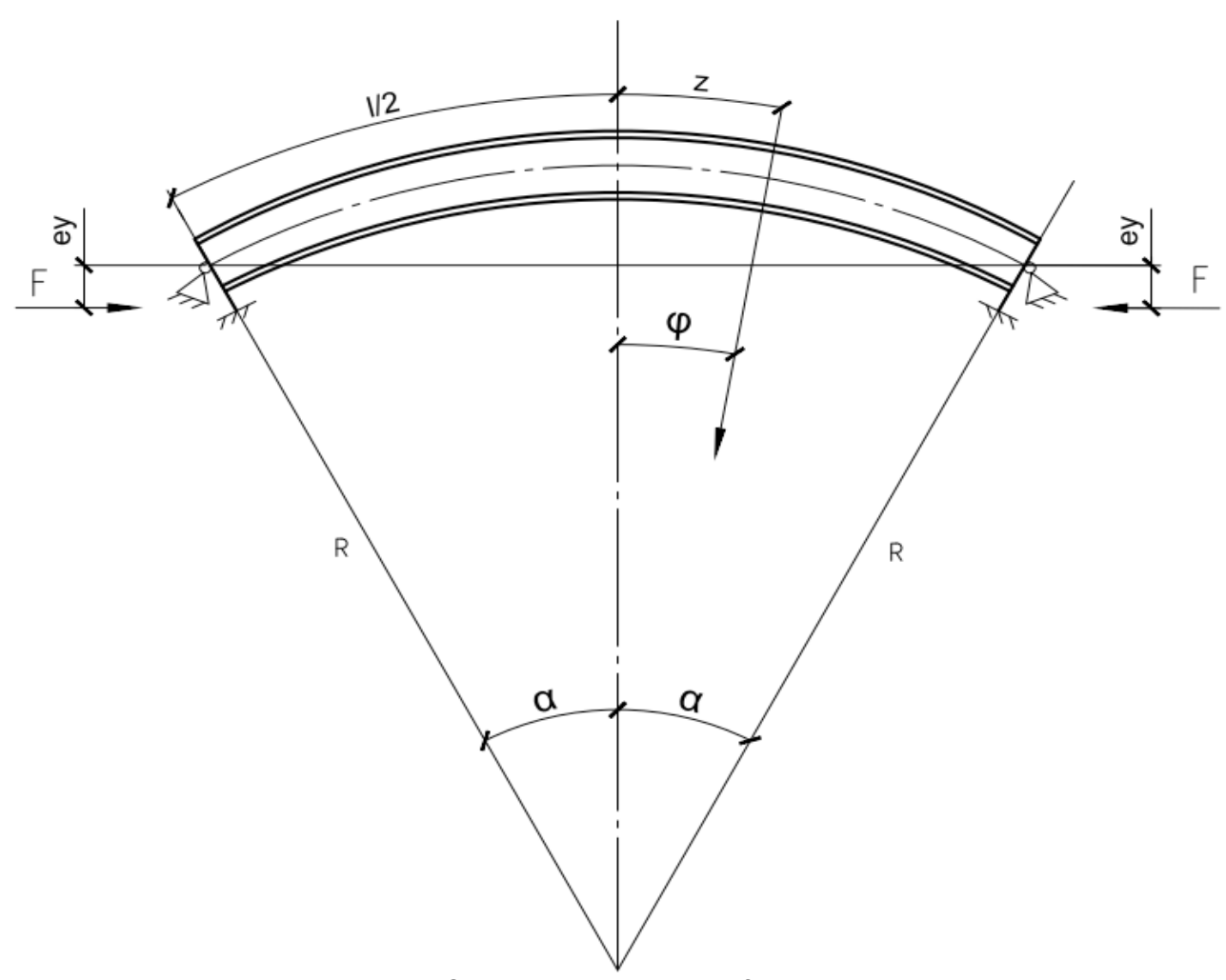

Figure 2. Computational scheme of the element 
To solve the set problem, let us apply the system of stress-strain equilibrium equations of $E$. A. Beylin for curved axis rods. At accepted bracing conditions and the section shape, differential equilibrium equations of the rod will take the following form:

$$
\left\{\begin{array}{l}
E J_{y} X_{y}^{\prime \prime}-X_{y} N-X_{z}^{\prime} M_{x}-2 X_{z} M_{x}^{\prime}+\frac{1}{R}\left(G J_{k} X_{z}^{\prime}-E J_{\omega} X_{z}^{\prime \prime \prime}\right)=0 \\
E J_{\omega} X_{z}^{\prime \prime \prime}-G J_{k} X_{z}^{\prime}-X_{y}\left(M_{x}-\frac{E J_{y}}{R}\right)-i_{P}^{2}\left(X_{z} N\right)^{\prime}=0
\end{array}\right.
$$

where $X_{y}, X_{z}$ are unknown functions of components of the curved rod axis movement, which are found with the following equations:

$$
X_{y}=-v^{\prime \prime}+\frac{\theta}{R} ; X_{z}=\theta^{\prime}+\frac{v^{\prime}}{R}
$$

$E, G$ are modules of linear and shear deformation; $J_{y}$ and $J_{\omega}$ are the main axial and sectorial moments of section inertia; $J_{k}$ is the moment of inertia of bending-prevented torsion; $i_{p}$ is the polar radius of inertia; $v$ is the lateral displacement of the rod axis, $\theta$ is the angle of rod curling.

Values of force factors acting along the rod length, with account for the curvature of the rod, take the following form:

$$
\begin{aligned}
& M_{x}=F R(\cos \varphi-\cos \alpha)+F e_{y} \\
& M_{y}=F E_{x} \cos \varphi \\
& N=F \cos \varphi \\
& M_{z}=F e_{x} \sin \varphi
\end{aligned}
$$

To calculate the equation system (1), let us use the analytical-numerical procedure; wherein the general solution of the problem upon the elastic work of the material is represented in the form of the combination of particular solutions:

$\chi_{y}=\chi_{y, s t r}+\chi_{y, s t} ; \chi_{z}=\chi_{z, s t r}+\chi_{z, s t}$

The first summands are solutions of equations compiled according to the strainless calculation scheme:

$$
E J_{y} \chi_{y, s t r}=M_{y} ; G J_{k} \chi_{z, s t r}-E J_{\omega} \chi_{z, s t r}^{\prime \prime}=M_{z}
$$

Let us substitute values of force factors (3) into equations (5) and obtain the following:

$$
\begin{aligned}
& E J_{y} \chi_{y, s t r}=F e_{x} \cos \varphi ; \\
& G J_{k} \chi_{z, s t r}-E J_{\omega} \chi_{z, s t r}^{\prime \prime}=F e_{x} \sin \varphi
\end{aligned}
$$

Transforming equations (6):

$\chi_{y, s t r}=\frac{F \cdot e_{x}}{E J_{y}} \cos \varphi ;$

$-\chi_{z, s t r}^{\prime \prime}+\frac{G J_{k}}{E J_{\omega}} \chi_{z, s t r}=\frac{F e_{x}}{E J_{\omega}} \sin \varphi$

Solving the set equations (7), we obtain:

$$
\begin{aligned}
& \chi_{y, s t r}=\frac{F \cdot e_{x}}{E J_{y}} \cos \varphi ; \\
& \chi_{z, s t r}=\frac{F \cdot e_{x} \cdot R^{2}}{E J_{\omega}}\left(\frac{\sin \varphi}{\left(k^{2} R^{2}+1\right)}-s h(k z) .\right.
\end{aligned}
$$

$\frac{\cos \alpha}{k \cdot \operatorname{ch}\left(\frac{k l}{2}\right)}\left(\frac{e_{y}}{R^{2}}+\frac{1}{\left(k^{2} R^{2}+1\right) R}\right)$

where $k=\frac{G J_{k}}{E J_{\omega}} ; \varphi=\frac{z}{R}$

The second summands in (3) are functions of the stability loss, which follow from the solution of bifurcation stability problems. With account for the set calculation scheme, the loss-of-stability functions will take the following form:

$\chi_{y, s t}=\chi_{y, s t} \cos \frac{\pi z}{l} ; \quad \chi_{z, s t}=\chi_{z, s t} \sin \frac{\pi z}{l}$

Where $\cos (\pi z / l)$ and $\sin (\pi z / l)$ are forms of the stability loss, and $X_{y, y}$ and $X_{z, y}$ are some unknown constants.

Let us substitute the values of solutions (4) in (1), considering (8) and (9), and obtain the following: 


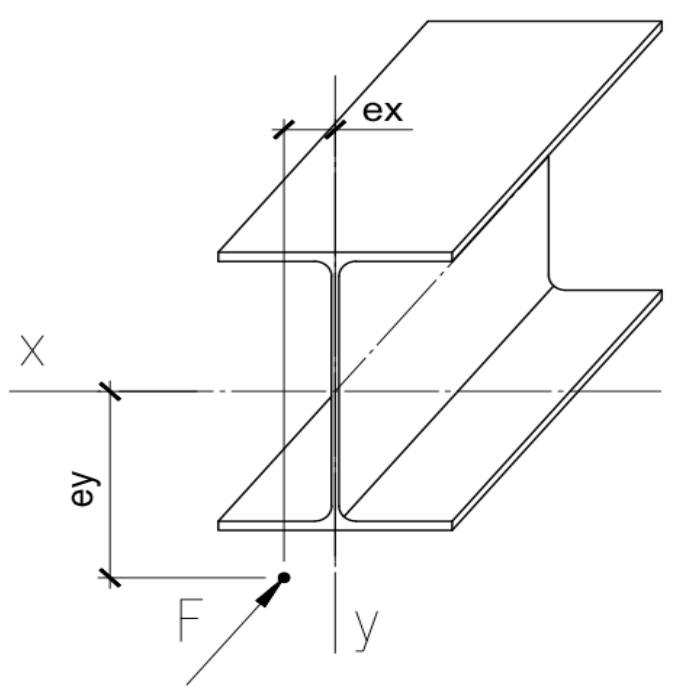

(a)

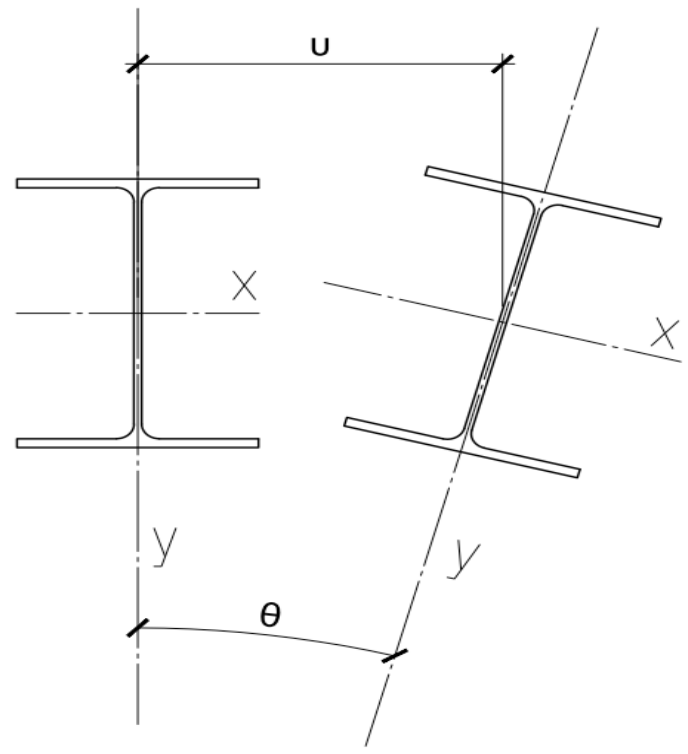

(b)

Figure 3. $a$ - loading scheme; $b$-spatial movements of sections

To solve the system (10), let us apply the algorithm of the Bubnov-Galerkin method:

$$
\left\{\begin{array}{l}
\int_{0}^{\frac{l}{2}} L_{y} \cos \frac{\pi z}{l} d z=0 \\
\frac{l}{2} \int_{0}^{\frac{l}{2}} L_{z} \sin \frac{\pi z}{l} d z=0
\end{array}\right.
$$

As a result, we will obtain systems of two algebraic equations relative to unknown constants $X_{y, y}$ and $X_{z, y}$. Having solved this system, we will obtain all components of movements. Substituting values $X_{y}$ and $X_{z}$ in (2) and solving the system of differential equations, we will obtain values of $v$ and $\theta$, which allow proceeding to strain stresses:

$M_{y}=M_{y}^{0}+N^{0} v+M_{x}^{0} \theta ; \quad B_{\omega}=-E J_{\omega} \theta^{\prime \prime}$

Taking into account (12), let us present the values of stresses in the rod middle section:
$\sigma=\frac{N}{A}+\frac{M_{x}^{0}}{W_{x}}+\frac{M_{y}^{0}+N^{0} v+M_{x}^{0} \theta}{W_{y}}+\frac{B_{\omega}}{W_{\omega}} \leq R_{y}$

Let us divide both sides of the equation (13) by $R_{y}$ and take N/ARy out of the brackets.

After a number of transformations, the equation (13) will take the following form:

$\frac{N}{A R_{y}}\left(1+m_{x}^{0}+m_{y}^{0}+\frac{v(0)}{\rho_{y}}+\frac{e_{y} \theta(0)}{\rho_{y}}+\frac{B_{\omega}}{N \rho_{\omega}}\right) \leq 1$

Where $m_{x}, m_{y}$ are relative eccentricities; $\rho x, \rho y$ are radii of section cores.

The resulting expression allows determining the critical load values.

Thus, the above algorithm makes it possible to assess stability of circular axis rods by the flexural-torsional form according to the fibrous yield criterion.

\section{Example of calculation}

As an illustration of the calculation procedure, an example of the section selection for a steel arch with the run of $36 \mathrm{~m}$, the rising height of $8.5 \mathrm{~m}$, and the interval of runs of $5.0 \mathrm{~m}$ is stated.

Preliminary, let us take the arch section as 70Б0 I-beam according to the industry standard STO ASChM 20-93, the material of construction - C245 steel.

The arch stability in the plane is considered to be ensured. 


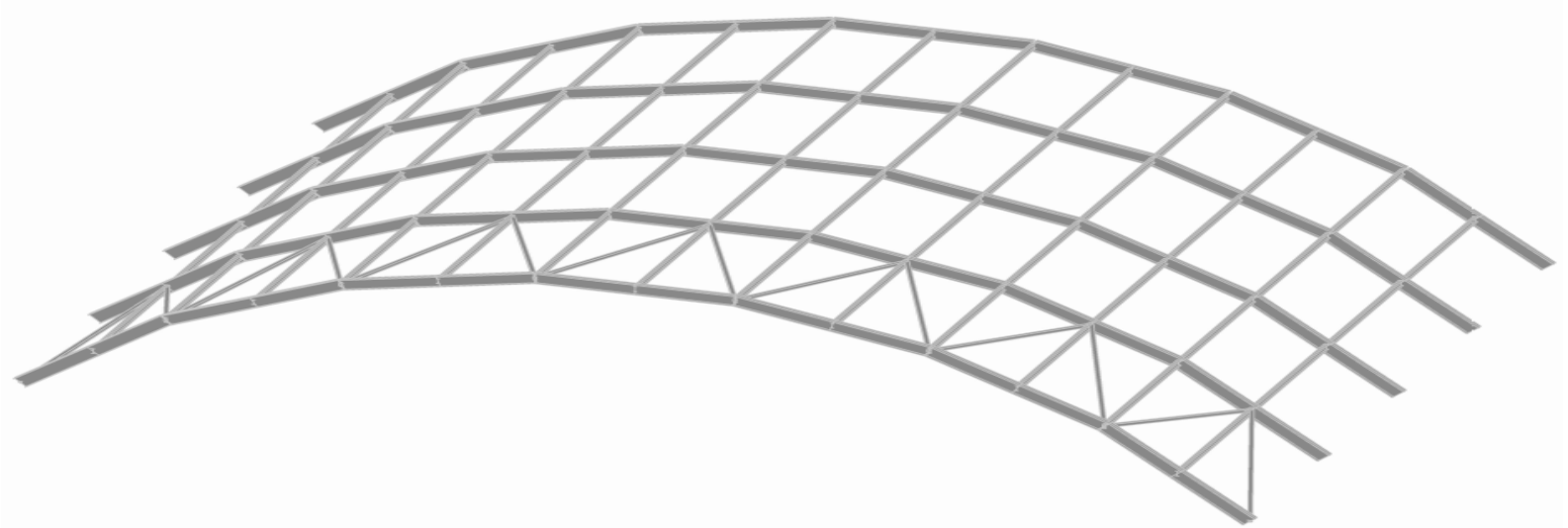

Figure 4. Fragment of a building frame

Let us select from the arch a rod element between runs of $5.0 \mathrm{~m}$ length. The following boundary forces were obtained in the selected fragment of the arch upon calculation of the structure in the plane against the action of permanent and temporary loads:

$$
N=-100 t ; M_{x}=24 t m
$$

Let us write the value of the eccentricity in the arch plane, taking into account the bending out of the plane of the arch in connection with a random eccentricity:

$e_{y}=\frac{M_{x}^{0}}{N}=\frac{9.4 t m}{40 t}=0.235 \mathrm{~m}=23.5 \mathrm{~cm}$

Taking into account the set calculation scheme and obtained forces and applying the above algorithm, we obtain the following values of the arch rod element axis displacement in the middle section:

$e_{x, \text { rand }}=\frac{l_{e f y}}{750}+\frac{i_{y}}{20}=\frac{317.5}{750}+\frac{4.5}{20}=0.65 \mathrm{~cm}$ where $v$ is the lateral displacement of the rod axis; $\theta$ is the angle of the rod curling

Taking into account the obtained displacements, let us write the values of strain forces My (the moment out of the arch plane caused by random eccentricity $\left.e_{x, \text { rand }}\right) B_{w}$ :

$M_{y}=0.92 t m ; B_{\omega}=0.13 t \cdot \mathrm{cm}^{2}$

In accordance with the equation (14), let us determine the factor of the section use:

$\frac{N}{A R_{y}}\left(1+m_{x}^{0}+m_{y}^{0}+\frac{v(0)}{\rho_{y}}+\frac{e_{y} \theta(0)}{\rho_{y}}+\frac{B_{\omega}}{N \rho_{\omega}}\right)=0,978 \approx 1$

Taking into account the set loads, the factor of the section use is close to one, therefore, the section is chosen correctly.

Thus, the above stated algorithm makes it possible to assess the stability of rods with the circular axis by the flexural-torsional form according to the fibrous yield criterion. 


\section{References}

Askinazi, V.Y. (2015). Prostranstvennaia ustoichivost dvutavrovykh sterzhnei s peremennoi vysotoi stenki v uprugo-plasticheskoi stadii [Overall stability of tapered I-section members in elastoplastic stage]. Vestnik grazhdanskikh inzhenerov [Bulletin of Civil Engineers], 4 (51), pp.46-55. (in Russian)

Beliy, G.I. (1973). Nekotorye voprosy deformatcionnogo rascheta i ustoichivosti tonkostennykh sterzhnei s ploskoi krivolineinoi osiu [Some issues of the strain calculation and the stability of thin-walled rods with the plane curved axis]. PhD thesis in Engineering. Leningrad: Leningrad Civil Engineering Institute, p.130. (in Russian)

Beliy, G.I. (1987). Prostranstvennaia rabota i predelnye sostoianiia sterzhnevykh elementov metallicheskikh konstrutcii [Spatial work and limit states of rod elements in metal structures]. D.Sc. thesis in Engineering. Leningrad: Leningrad Civil Engineering Institute, p.464. (in Russian)

Beylin, E.A. (1970). K teorii deformatcionnogo rascheta i ustoichivosti krivolineinykh i priamolineinykh tonkostennykh sterzhnei [To the theory of the strain calculation and the stability of curved axis and straight thin-walled rods]. Mechanics of rod systems and continuous media, 63, pp.5-19. (in Russian)

Beylin, E.A. (1997). Statika i dinamika tonkostennykh krivolineinykh sterzhnei proizvolngo profilia [Statics and dynamics of thin-walled curved axis rods of an unspecified shape]. News of Higher Educational Institutions. Construction, 7, pp.19-26. (in Russian)

Guinot, F., Bourgeois,S., Cochelin, B., Blanchard, L. (2012). A planar rod model with flexible thin-walled cross-sections. Application to the folding of tape springs. International Journal of Solids and Structures, 49(1), pp.73-86. DOI: 10.1016/j.ijsolstr.2011.09.011

Kolokolov, S.B. (2010). Issledovanie protcessa deformirovaniia arochnoi konstruktcii kak sposob otcenki ee ustoichivosti [Investigation of the process of deformation of an arch structure as a way of assessing its stability]. Vestnik of the Orenburg State University, 2(108), pp.150-153. (in Russian)

Kolokolov, S.B. (2014). Issledovanie ustoichivosti stalnoi parabolicheskoi arki deformatcionnym metodom [Investigation of the stability of a steel parabolic arch using the deformation method]. In: Proceedings of the International Scientific and technical Conference "Construction Science - 2014: Theory, Education, Practice, Innovation", Arkhangelsk: Publishing house "printing office Tochka", pp.213-217. (in Russian)

Kolokolov, S.B. (2015). Metodika podbora secheniia stalnoi arki pri pomoshchi deformatcionnogo rascheta [The method of selecting the section of a steel arch using deformation calculation]. Vestnik of the Orenburg State University, 5(180), pp.151-154. (in Russian)

Kuznetcov, A.Y. (2013). Prochnost i prostranstvennaia ustoichivost sostavnykh sterzhnevykh elementov konstruktcii iz kholodnognutykh profilei [Strength and spatial stability of composite structural elements from cold-formed profiles]. PhD thesis in Engineering. Saint Petersburg: Saint Petersburg State University of Architecture and Civil Engineering, p.142. (in Russian)

Timoshenko, S.P. (1971). Ustoichivost sterzhnei, plastin i obolochek [Stability of rods, plates and shells]. Moscow: Nauka, p.808. (in Russian)

Trubina, D., Abdulaev, D., Pichugin, E., Garifullin, M. (2014). The Loss of Local Stability of Thin-Walled Steel Profiles. Applied Mechanics and Materials, 633-634, pp. 1052-1057. DOI: 10.4028/www.scientific.net/AMM.633-634.1052

Vlasov, V.Z. (1959). Tonkostennye uprugie sterzhni [Thin-walled elastic rods]. Moscow: Fizmatgiz, p.568. (in Russian) 